\title{
Upper Limb Ischemia Following COVID-19 Infection: A Case Report
}

\author{
Mohsen Arabi ${ }^{1}$, Hazhir Heidari Beigvand ${ }^{2}$, HamidReza Samimagham ${ }^{3}$, Nastaran Salimi ${ }^{4}$ and Mitra \\ Kazemi Jahromi (iD) ${ }^{5, *}$
}

\author{
${ }^{1}$ Department of Family Medicine, Preventive Medicine and Public Health Research Center, Iran University of Medical Sciences, Tehran, Iran \\ ${ }^{2}$ Firoozabadi Research Development Center, Faculty of Medicine, Iran University of Medical Sciences, Tehran, Iran \\ ${ }^{3}$ Clinical Research Development Center, Shahid Mohammadi Hospital, Hormozgan University of Medical Sciences, Bandar Abbas, Iran \\ ${ }^{4}$ Student Research Committee, Iran University of Medical Sciences, Tehran, Iran \\ ${ }^{5}$ Endocrinology and Metablism Research Center, Hormozgan University of Medical Sciences, Bandar Abbas, Iran \\ "Corresponding author: Endocrinology and Metablism Research Center, Hormozgan University of Medical Sciences, Bandar Abbas, Iran. Email:
} mitra.kazemijahromi@gmail.com

Received 2021 December 27; Revised 2022 February 05; Accepted 2022 February 05.

\begin{abstract}
Introduction: COVID-19 infection can cause a wide range of complications, from respiratory infection to skin rashes.

Case Presentation: Here, we report a case of a 73-year-old woman with left brachial artery thrombosis 2 weeks after the onset of COVID-19 infection, leading to left upper limb ischemia.

Conclusions: Given the life-changing nature of limb ischemia that can lead to amputation, it is crucial to consider it from the beginning of COVID-19 infection and think of preventive measures in this pandemic.
\end{abstract}

Keywords: COVID-19, Ischemia, Upper Limb

\section{Introduction}

COVID-19 has shocked the world not only by affecting people's lives in many ways, but also by causing various complications from respiratory infection to skin rashes (1). The ability of the virus to hide behind the mask of various symptoms adds to the risk of leaving permanent sequels, a mystery that needs to be gradually discovered. Coagulopathy is a serious complication that occurs in 20 - 55\% of the patients (2). The most common coagulopathies are respectively deep vein thrombosis (DVT), pulmonary embolism (PE), ischemic stroke, and myocardial infarction. Data about peripheral arterial events in COVID-19 are limited, and despite a number of reports on lower limb ischemia, upper limb ischemia is quite rare $(3,4)$. Here, we report a case of a 73-year-old woman with a history of noninsulin-dependent diabetes and hypertension who developed left brachial artery thrombosis 2 weeks after the onset of COVID-19 infection, leading to left upper limb ischemia.

\section{Case Presentation}

A 73-year-old woman was admitted to the emergency department of Firoozabadi Hospital on July 10, 2020, with fever, hypoxia, and loss of consciousness. According to her family, her initial symptoms (including dyspnea, fatigue, and fever) had been going on for 2 weeks, but she refused to seek medical advice earlier due to fear of the pandemic. Her past medical history included non-insulin-dependent diabetes and hypertension. She was a non-smoker and did not consume alcohol. She was transferred to the hospital by paramedics and had already received supplemental oxygen; therefore, her peripheral oxygen saturation was $90 \%$. She was hemodynamically unstable with a blood pressure of $90 / 60 \mathrm{~mm} \mathrm{Hg}$ and a heart rate of $90 \mathrm{bpm}$. Her body temperature was $38.1^{\circ} \mathrm{C}$, and her Glasgow Coma Scale (GCS) was 10/15. The initial laboratory findings revealed leukocytosis, thrombocytosis, elevated blood urea nitrogen (BUN), creatinine, creatine phosphokinase (CPK), lactate dehydrogenase (LDH), troponin, and C-reactive protein (CRP; see Table 1).

A chest computed tomography (CT) scan revealed diffused patchy ground-glass opacities and consolidation in both lungs (Figure1), and she was given lopinavir/ritonavir, ceftriaxone, azithromycin, dexamethasone, enoxaparin, and paracetamol. Two weeks after the onset of symptoms (a few hours after admission to the hospital), she suddenly developed mottling in her left forearm; her left hand turned cold and pale, and there were no palpable radial 


\begin{tabular}{|c|c|}
\hline Variables & Values \\
\hline White cell count ( per $\mathbf{m m}^{3}$ ) & 15400 \\
\hline Neutrophil (per mm³) & 13444 \\
\hline Lymphocyte (per mm³) & 1185 \\
\hline Red cell count (million per $\mathbf{m m}^{\mathbf{3}}$ ) & 5.25 \\
\hline $\operatorname{Hemoglobin}(\mathrm{g} / \mathrm{dL})$ & 15.2 \\
\hline Platelet count (per mm ${ }^{3}$ ) & 736000 \\
\hline Prothrombin time (s) & 17 \\
\hline International normalized ratio (index) & 1.5 \\
\hline Partial thromboplastin time (s) & 42 \\
\hline Blood glucose (mg/dL) & 484 \\
\hline BUN (mg/dL) & 93 \\
\hline Creatinine $(\mathrm{mg} / \mathrm{dL})$ & 3.3 \\
\hline Aspartate aminotransferase $(\mathrm{U} / \mathrm{L})$ & 42 \\
\hline Alanine aminotransferase $(\mathrm{U} / \mathrm{L})$ & 31 \\
\hline Lactate dehydrogenase $(\mathrm{U} / \mathrm{L})$ & 1485 \\
\hline Creatine phosphokinase $(\mathrm{U} / \mathrm{L})$ & 710 \\
\hline Alkaline phosphatase $(\mathrm{U} / \mathrm{L})$ & 216 \\
\hline Total bilirubin (mg/dL) & 2 \\
\hline Direct bilirubin (mg/dL) & 0.6 \\
\hline Serum $\mathrm{Na}(\mathrm{mmol} / \mathrm{L})$ & 156 \\
\hline $\operatorname{Serum~K}(\mathbf{m m o l} / \mathbf{L})$ & 2.6 \\
\hline $\operatorname{Troponin}(\mathbf{n g} / \mathbf{L})$ & 50.7 \\
\hline C-reactive protein $(\mathrm{mg} / \mathrm{L})$ & 64.2 \\
\hline
\end{tabular}

and ulnar pulses. Color Doppler ultrasonography was immediately performed, reporting the absence of blood flow in the distal third of the left brachial artery, and the tardus parvus pattern in the ulnar and radial arteries suggested proximal occlusion. Her unstable condition did not allow surgical intervention to remove the thrombosis; therefore, 5000 units of heparin was administered as a stat dose and then continued at 800 units per hour. No improvements were observed. Additionally, her clinical condition deteriorated, and her respiratory failure progressed. She was intubated some hours after admission, and despite all the efforts, she passed away 72 hours after admission.

\section{Discussion}

There is still a great deal that we do not know about the mechanisms by which SARS-CoV-2 affects the organs. Since the beginning of the pandemic, various studies have suggested coagulopathy as a relatively common complication and reported a correlation between the severity of infection and coagulation disturbances (4). That is why an anticoagulant agent is usually added to the regimen as prophylaxis in severe cases (5). There are cases reported all around the world that develop vein thrombosis (DVT), (pulmonary thromboembolism) PTE, or ischemia despite receiving anticoagulant agents; however, some studies have reported cases of ischemia with COVID-19 infection $(6,7)$. Studies have shown an association between COVID-19 infection and hypercoagulability state. Tang et al. showed that high D-dimer and fibrin degradation product levels were higher in patients who died of COVID-19 infection (8). Ischemia in a healthy non-atherosclerotic artery is rare, but it has been reported in COVID-19 infection (9-12). The incidence of acute limb ischemia in COVID-19 patients was reported to be about $0.9 \%$ (9), which is higher than that in the general population (13) and hospitalized patients with cancer (14). Therefore, this condition is important in this population. The reason why severe complications due to coagulopathy still occur despite prophylactic measurements is unknown. Life-threatening coagulopathies (such as PTE or myocardial infarction) usually occur immediately, but limb ischemia might be missed due to their lower incidence.

\subsection{Conclusions}

Given the life-changing nature of limb ischemia that can lead to amputation, it is crucial to consider it from the beginning of COVID-19 infection and think of preventive measures. We hope we are being able to find effective solutions for this problem in the near future.

\section{Footnotes}

Authors' Contribution: M. A. and M. KJ. contributed to the conception, design, and statistical analysis. Other authors contributed to data collection and manuscript drafting. M. KJ. supervised the study. All authors approved the final version of the manuscript.

Conflict of Interests: The authors have no conflict of interest.

Ethical Approval: The Ethics Committee of Iran University of Medical Sciences approved this study (code: IR.IUMS.FMD.REC.1400.192).

Funding/Support: This study was supported by the Firoozabadi Research Development Center, Iran University of Medical Sciences, Tehran, Iran.

Informed Consent: Written informed consent was obtained from the patient. 


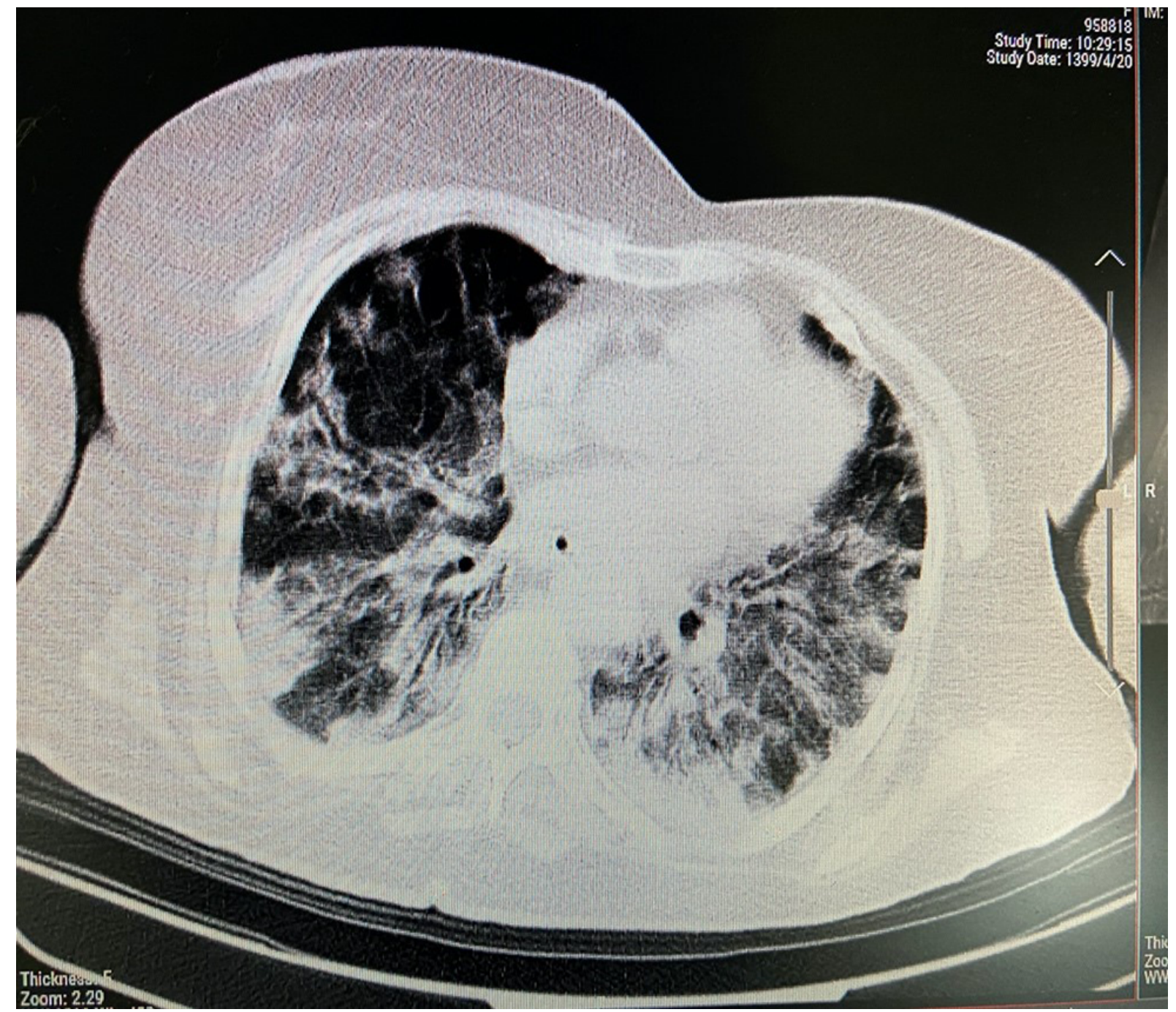

Figure 1. Diffuse patchy ground-glass opacities and consolidation in both lungs

\section{References}

1. Gottlieb M, Long B. Dermatologic manifestations and complications of COVID-19. Am J Emerg Med. 2020;38(9):1715-21. doi: 10.1016/j.ajem.2020.06.011. [PubMed: 32731141]. [PubMed Central: PMC7274995].

2. Lee SG, Fralick M, Sholzberg M. Coagulopathy associated with COVID19. CMAJ. 2020;192(21). E583. doi: 10.1503/cmaj.200685. [PubMed: 32357997]. [PubMed Central: PMC7259970].

3. Becker RC. COVID-19 update: Covid-19-associated coagulopathy. $J$ Thromb Thrombolysis. 2020;50(1):54-67. doi: 10.1007/s11239-020-021343. [PubMed: 32415579]. [PubMed Central: PMC7225095].

4. Kashi M, Jacquin A, Dakhil B, Zaimi R, Mahe E, Tella E, et al. Severe arterial thrombosis associated with Covid-19 infection. Thromb Res. 2020;192:75-7. doi: 10.1016/j.thromres.2020.05.025. [PubMed: 32425264]. [PubMed Central: PMC7229939].

5. Tobaiqy M, Qashqary M, Al-Dahery S, Mujallad A, Hershan AA, Kamal MA, et al. Therapeutic management of patients with COVID-
19: a systematic review. Infect Prev Pract. 2020;2(3):100061. doi: 10.1016/j.infpip.2020.100061. [PubMed: 34316558]. [PubMed Central: PMC7162768].

6. Bellosta R, Luzzani L, Natalini G, Pegorer MA, Attisani L, Cossu LG, et al. Acute limb ischemia in patients with COVID-19 pneumonia. $J$ Vasc Surg. 2020;72(6):1864-72. doi: 10.1016/j.jvs.2020.04.483. [PubMed: 32360679]. [PubMed Central: PMC7188654].

7. Galanis N, Stavraka C, Agathangelidis F, Petsatodis E, Giankoulof C, Givissis P. Coagulopathy in COVID-19 infection: a case of acute upper limb ischemia. J Surg Case Rep. 2020;2020(6):rjaa204. doi: 10.1093/jscr/rjaa204. [PubMed: 32661487]. [PubMed Central: PMC7332286].

8. Tang N, Li D, Wang X, Sun Z. Abnormal coagulation parameters are associated with poor prognosis in patients with novel coronavirus pneumonia.J Thromb Haemost. 2020;18(4):844-7. doi: 10.1111/jth.14768. [PubMed: 32073213]. [PubMed Central: PMC7166509]. 
9. Nasab EM, Heidarzadeh S, Yavari B, Athari SS. Acute upper limb ischemia in a patient with COVID-19: A case report. Ann Vasc Surg. 2021;77:83-5.

10. Galyfos G, Sianou A, Frountzas M, Vasilios K, Vouros D, Theodoropoulos C, et al. Acute limb ischemia among patients with COVID-19 infection. J Vasc Surg. 2022;75(1):326-42. doi: 10.1016/j.jvs.2021.07.222. [PubMed: 34390791]. [PubMed Central: PMC8358086].

11. Makhoul K, Shukha Y, Hanna LA, Nitecki S, Leiderman M, Hayek $\mathrm{T}$, et al. A case of rapidly progressive upper limb ischemic necrosis in a patient with COVID-19. Int J Infect Dis. 2021;106:401-4. doi: 10.1016/j.ijid.2021.04.023. [PubMed: 33862207]. [PubMed Central: PMC8056782].

12. Shao T, In-Bok Lee C, Jabori S, Rey J, Duran ER, Kang N. Acute upper limb ischemia as the first manifestation in a patient with COVID-19. J Vasc Surg Cases Innov Tech. 2020;6(4):674-7. doi: 10.1016/j.jvscit.2020.08.003. [PubMed: 32844136]. [PubMed Central: PMC7441069].

13. Howard DP, Banerjee A, Fairhead JF, Hands L, Silver LE, Rothwell PM, et al. Population-Based Study of Incidence, Risk Factors, Outcome, and Prognosis of Ischemic Peripheral Arterial Events: Implications for Prevention. Circulation. 2015;132(19):1805-15. doi: 10.1161/CIRCULATIONAHA.115.016424. [PubMed: 26350058]. [PubMed Central: PMC4633967].

14. Khorana AA, Francis CW, Culakova E, Fisher RI, Kuderer NM, Lyman GH. Thromboembolism in hospitalized neutropenic cancer patients. J Clin Oncol. 2006;24(3):484-90. doi: 10.1200/JCO.2005.03.8877. [PubMed: 16421425]. 